\title{
Influence of intermetallic particles on short fatigue crack initiation in AA2050-T8 and AA7050-T7451
}

\author{
Erembert Nizery ${ }^{1,2, a}$, Jean-Yves Buffiere ${ }^{1}$, Henry Proudhon $^{2}$, Armelle Daniélou ${ }^{3}$ and Samuel Forest ${ }^{2}$ \\ ${ }^{1}$ INSA Lyon, MATEIS, 25 av. Jean Capelle, 69621 Villeurbanne Cedex, France \\ ${ }^{2}$ Mines ParisTech, Centre des Matériaux, BP. 87, 91003 Evry, France \\ ${ }^{3}$ Constellium CRV, 725 rue Aristide Bergès, CRV CS 10027, 38341 Voreppe, France
}

\begin{abstract}
Fatigue crack initiation at particles is studied in hot rolled 2050-T8 and 7050T7451 material, using 1 to $4 \mathrm{~mm}$ cross section specimens. Both size and aspect ratio of particles are observed to affect their probability of being damaged. In 2050-T8 material, the probability that a matrix crack initiate at a cracked particle increases with its size, and no effect of aspect ratio is observed. In 2050-T8 specimens, matrix cracks initiate at both precracked $(\mathrm{Al}, \mathrm{Cu}, \mathrm{Fe}, \mathrm{Mn})$ particles and particles cracked during cycling. Initiation in 7050$\mathrm{T} 74$ specimens occur on $\mathrm{Mg}_{2} \mathrm{Si}$ particles which may be cracked or debonded, and $\mathrm{Al}_{7} \mathrm{Cu}_{2} \mathrm{Fe}$ particles that are cracked during cyclic loading.
\end{abstract}

\section{Introduction}

In several high-strength aluminum alloys, fatigue initiation is known to occur at large particles [1]. In this study, initiation at particles is discussed in a 2050-T8 and a 7050-T7451 plate. Large particles in 2050 plate are identified to contain (Al, $\mathrm{Cu}, \mathrm{Fe}, \mathrm{Mn}$ ) elements; 7050 plate contains particles identified as $\mathrm{Al}_{7} \mathrm{Cu}_{2} \mathrm{Fe}$ and $\mathrm{Mg}_{2} \mathrm{Si}$.

\section{Materials and method}

For this experiment, rolled plates of material in 2050-T8 $(60 \mathrm{~mm})$ and 7050-T7451 $(65 \mathrm{~mm})$ were used. Composition and mechanical properties are described in [2-3]. Specimens with cross-section between 1 and $4 \mathrm{~mm}$ were machined at 1/4 thickness along rolling direction (RD), and the flat surfaces (RD-TD Transverse Direction) were polished using SiC papers, diamond solutions $(3 \mu \mathrm{m}$ and $1 \mu \mathrm{m})$ and finally a colloidal silica solution $(0.05 \mu \mathrm{m})$. Curved surfaces are polished up to $4000 \mathrm{SiC}$ paper.

At initial state, particles are observed at magnifications of at least x2000 with a Scanning Electron Microscope (SEM) in Secondary Electrons mode (SE) on one surface of each specimen. Specimens are then cycled in a fatigue machine for several thousand cycles $\left(\mathrm{R}=0.1, \mathrm{f}=20 \mathrm{~Hz}, \sigma_{\max }=330-360 \mathrm{MPa}\right)$, until crack initiations are detected. SEM-SE images are then compared to those of initial state, and image analysis is performed.

a Corresponding author: erembert.nizery@mines-paris.org

This is an Open Access article distributed under the terms of the Creative Commons Attribution License 4.0, which permits unrestricted use, distribution, and reproduction in any medium, provided the original work is properly cited. 


\section{Results and discussion}

The examination of 2050 and 7050 specimens shows that (Al, $\mathrm{Cu}, \mathrm{Fe}, \mathrm{Mn}$ ) particles as well as $\mathrm{Mg}_{2} \mathrm{Si}$ might be damaged at initial state, before any mechanical loading (Fig 1, left). This was only observed in very few cases for $\mathrm{Al}_{7} \mathrm{Cu}_{2} \mathrm{Fe}$ particles. Image analysis revealed that large particles and the ones elongated in $\mathrm{RD}$ are more likely to crack [3]. For $\mathrm{Mg}_{2} \mathrm{Si}$ over $12 \mu \mathrm{m}$ equivalent diameter and (Al, $\mathrm{Cu}, \mathrm{Fe}, \mathrm{Mn}$ ) particles over $15 \mu \mathrm{m}$ (in RD-TD plane), more than one half are cracked.
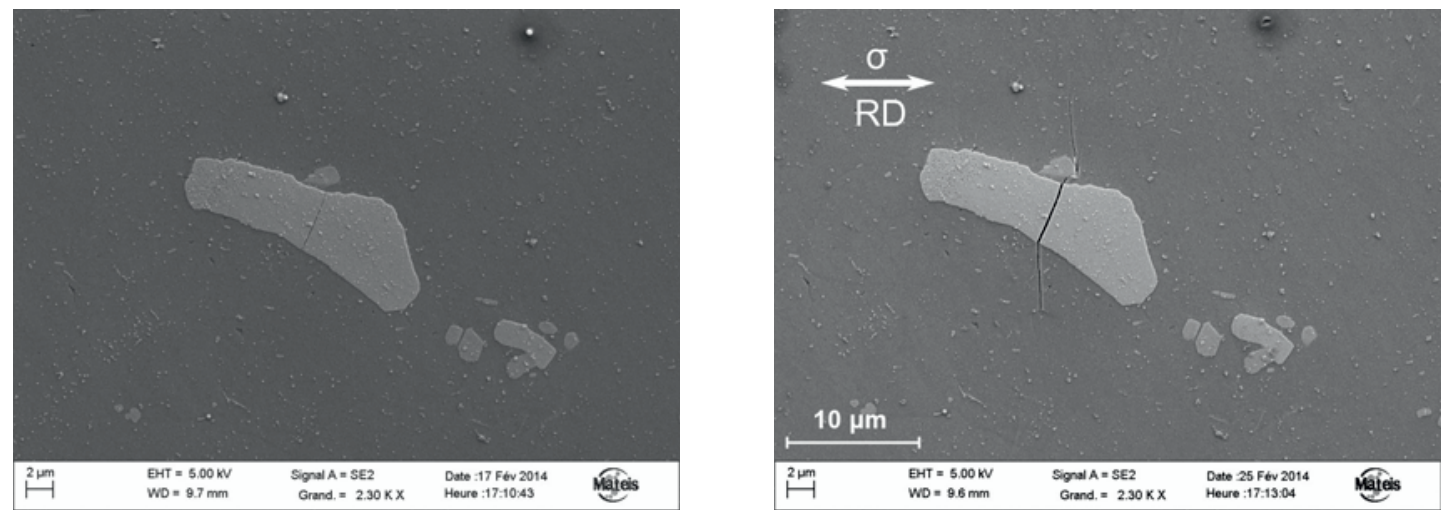

Figure 1. SEM-SE image of an (Al, Cu, Fe, Mn) particle in a 2050-T8 specimen, (left) at initial state and (right) after 11000 cycles (330 Mpa).

Cracked particles leading to matrix cracks were distinguished from cracked ones that did not initiate in 2050 specimens. Among cracked ( $\mathrm{Al}, \mathrm{Cu}, \mathrm{Fe}, \mathrm{Mn}$ ) particles, 20\% have led to matrix cracks. It is observed that the larger particles initiate more easily matrix cracks, which is consistent with the classical model of projected defect area [4]. The shape ratio of particles, however, seems to have a negligible influence on the matrix crack initiation step.

After cycling loading in 2050 specimens, new cracked particles were observed. Although they represented less than $10 \%$ of the overall cracked particles, almost all of these new cracked particles initiated cracks and accounted for one third of matrix cracks. For specimens in 7050 alloy, cracks initiated at both cracked or debonded $\mathrm{Mg}_{2} \mathrm{Si}$ and cracked $\mathrm{Al}_{7} \mathrm{Cu}_{2} \mathrm{Fe}$. Differences in Young's modulus for these particles have already been reported [5], which could explain those observations.

\section{Conclusion}

This study has shown that pre-cracked particles as well as those cracked during loading may lead to matrix crack initiation in 2050-T8 and 7050-T7451 plates. Particles size both affect particle cracking and matrix crack initiation, whereas aspect ratio with respect to the rolling direction only influence particle cracking. Differences are observed between (Al, $\mathrm{Cu}, \mathrm{Fe}, \mathrm{Mn}$ ), $\mathrm{Al}_{7} \mathrm{Cu}_{2} \mathrm{Fe}$ and $\mathrm{Mg}_{2} \mathrm{Si}$ particles, which suggest that their behaviour should be taken into account when predicting initiation.

\section{References}

1. S. Suresh, Fatigue of materials (Cambridge University Press, 1998)

2. P. Lequeu, K.P. Smith, A. Daniélou, J. Mater. Eng. Perform. 19, 6 (2010)

3. E. Nizery, J.Y. Buffiere, H. Proudhon, A. Daniélou, S. Forest, Proc. of ICAA14 conf., Accepted

4. Y. Murakami, Metal fatigue: effects of small defects and nonmetallic inclusion (Elsevier, 2002)

5. G. Petton, PhD thesis (INSA Lyon, 1995) 